\title{
Aa. Vv., Correspondance de Pierre Bayle
}

\section{Franco Piva}

\section{(2) OpenEdition}

\section{Journals}

\section{Edizione digitale}

URL: http://journals.openedition.org/studifrancesi/27597

DOI: 10.4000/studifrancesi.27597

ISSN: 2427-5856

\section{Editore}

Rosenberg \& Sellier

\section{Edizione cartacea}

Data di pubblicazione: 31 décembre 2006

Paginazione: 605

ISSN: 0039-2944

\section{Notizia bibliografica digitale}

Franco Piva, «Aa. Vv., Correspondance de Pierre Bayle », Studi Francesi [Online], 150 (L | III) | 2006, online dal 30 novembre 2015, consultato il 08 novembre 2020. URL : http://journals.openedition.org/ studifrancesi/27597 ; DOI : https://doi.org/10.4000/studifrancesi.27597

\section{Questo documento è stato generato automaticamente il 8 novembre 2020.}

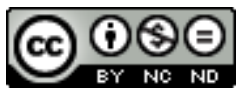

Studi Francesi è distribuita con Licenza Creative Commons Attribuzione - Non commerciale - Non opere derivate 4.0 Internazionale. 


\section{Aa. Vv., Correspondance de Pierre Bayle}

\section{Franco Piva}

\section{NOTIZIA}

Correspondance de Pierre Bayle. Tome IV janvier 1684-juillet 1684. Lettres 242-308.

Publiées et présentées par Elisabeth LABROUSSE et Anthony MCKENNA, Laurence BERGON, Hubert BOST, Wiep VAN BUNGEN, Edward JAMES, Anne LEROUX, Caroline VERDIER, Oxford, Voltaire Foundation, 2005, pp. XXI+ 287.

1 Presentiamo con piacere questo quarto volume della Correspondance de Pierre Bayle che una collaudata équipe messa in piedi e guidata da Elisabeth Labrousse e da Anthony McKenna, sta pubblicando per i tipi, altrettanto collaudati, della Voltaire Foundation. Dato il rinnovato interesse che da alcuni anni si è sviluppato attorno al filosofo di Rotterdam, l'idea di raccogliere in un corpus, filologicamente sicuro e accuratamente annotato, la corrispondenza di Pierre Bayle è stata non solo utile ma, in qualche modo indispensabile per una più approfondita e sicura conoscenza di un uomo, di uno scrittore e di un intellettuale che, a mano a mano che gli studi avanzano e si precisano, si rivela sempre più importante. L'augurio è quindi che l'impresa proceda speditamente e arrivi quanto prima alla sua conclusione.

2 All'inizio del 1684 Pierre Bayle è ormai un nome noto nella République des lettres. La Lettre sur les comètes, apparsa nel 1682 e riapparsa l'anno dopo sotto il titolo, più noro, di Pensées diverses, in particolare lo ha fatto conoscere ed apprezzare in tutta Europa. La rete dei suoi corrispondenti, come appare chiaramente da questo volume, è andata e va via via allargandosi e diversificandosi. Per conto del suo editore, Reinier Leers, Pierre Bayle tiene i contatti con diversi scrittori, soprattutto olandesi. Prosegue con i fratelli dei contatti che, specie con l'irrequieto Joseph, non si rivelano sempre facili. Soprattutto si assiste al lancio delle Nouvelles de la République des Lettres, il periodico con il quale l'editore Henri Desbordes intende sostituire l'incerto Mercure savant e che Bayle 
concepisce sul modello del Journal des savants. Per far fronte al nuovo impegno, al quale provvede quasi praticamente da solo, Bayle costruisce una fitta rete di contatti con scienziati, filosofi, intellettuali, scrittori de tous bords, cui chiedere informazioni e notizie utili al suo giornale, che a mano a mano che i mesi passano, si impone all'attenzione di un pubblico sempre più ampio sia per la qualità e la serietà delle informazioni, che per la precisione delle analisi e la correttezza dei giudizi, frutto di letture attente e meticolose, anche se defatiganti.

3 L'annotazione, abbondante e precisa, che accompagna le diverse lettere aiuta il lettore ad entrare in un mondo che a volte può sembrare distante, e che è invece quello stesso nel quale stava maturando quella rivoluzione intellettuale di cui Pierre Bayle è stato, indubbiamente, uno dei protagonisti. 